\title{
Empoderamento da mulher Kaiowa e Guarani na luta pelo reconhecimento dos direitos indígenas e identidade étnico-cultural
}

\author{
Angelica Maria Mejia Amado \\ UNIPD, Padua, Itália; Paris 1, Paris, França; KuLeuven, Bélgica e UCDB,Campo Grande,Brasil \\ Email: angelicamejiaamado@gmail.com \\ Cleonice Alexandre Le Bourlegat \\ UNIPD, Padua, Itália; Paris 1, Paris, França; KuLeuven, Bélgica e UCDB, Campo Grande,Brasil \\ Email: cleonice@lebourlegat.net \\ Antônio Hilário Aguilera Urquiza \\ Universidade Federal de Mato Grosso do Sul,Campo Grande,Brasil \\ Email: hilarioaguilera@gmail.com
}

\begin{abstract}
Resumo: Este artigo aborda as liderançasfemininasKaiowá e Guarani, suaspráticas e os motivos relatados por elas, naluta de resistência pelos direitos e conquista de maiorautonomia de gênero e de suas comunidades, no contexto em que se insere a Reserva Indígena de Dourados, no Mato Grosso do Sul / Brasil. O objetivo foi realizar umestudo etnográfico junto a essasmulheres indígenas, para interpretar por meio de suapercepções, os níveis de poder, que se tornaram foco dessasestratégias de lutafeminina. As informaçõesforamobtidas de fontes secundarias e primárias (entrevista semiestruturada, questionário), mediante umaanálisequali-quantitativa. O movimento feminista Kaiowaì e Guaranimanifesta-se emquatroníveis de empoderamento: (1) do indivíduo (2) da família (3) da comunidade (4) da sociedade, emboraaindahajamuitasdificuldades a serem superadas

Palavras chave: Empoderamento feminino; indígenas Kaiowa e Guarani; desenvolvimento territorial sustentável
\end{abstract}

\section{Empoderamiento de las mujeres kaiowa y guaraní en la lucha por el reconocimiento de los derechos indígenas y la identidad étnico-cultural}

\begin{abstract}
Resumen: Este artículo aborda el liderazgo femenino Kaiowá y Guarani, sus prácticas y las motivaciones evocadas por ellas, en la lucha de resistencia por los derechos y conquista de mayor autonomía de género y de sus comunidades, en el contexto en que se encuentra la Reserva Indígena de Dourados, en Mato Grosso del Sur / Brasil. El objetivo fue realizar un estudio etnográfico a estas mujeres, para interpretar por medio de su percepción, los niveles de poder, que se convirtieron en foco de esas estrategias de lucha femenina. La información se obtuvo de fuentes secundarias y primarias (entrevista semiestructurada, cuestionario), mediante un análisis cualitativo cuantitativo. El movimiento de mujeres Kaiowá y Guarani se manifiesta en cuatro niveles de empoderamiento: (1) del individuo (2) de la familia (3) de la comunidad (4) de la sociedad, aunque todavía hay muchas dificultades a superar.
\end{abstract}

Palabras clave: Empoderamiento femenino; indígenas Kaiowa-Guaraní; desarrollo territorial sostenible. 


\title{
Empowerment of Kaiowa and Guarani women in the struggle for the recognition of indigenous rights and ethnic-cultural identity
}

\begin{abstract}
This article addresses the female leadership Kaiowá and Guarani, their practices and the motivations evoked by them, in the struggle for rights and conquest of greater autonomy of gender and their communities, in the context of the Dourados Indigenous Reserve, in Mato Grosso do Sul / Brazil. The objective was to carry out an ethnographic study of these women in order to interpret, through their perception, the levels of power that became the focus of these strategies of female struggle. The information was obtained from secondary and primary sources (semi-structured interview, questionnaire), through a quantitative qualitative analysis. The Kaiowáand Guarani women's movement is expressed in four levels of empowerment: (1) of the individual (2) of the family (3) of the community (4) of the society, although there are still many difficulties to overcome.
\end{abstract}

Keywords: Women’s empowerment;Kaiowá and Guarani indigenous peoples; sustainable territorial development.

$* * *$

\section{Introdução}

O empoderamento feminino constitui o quinto objetivo do desenvolvimento sustentável (ODS) na construção da Agenda 2030 pela ONU. Indica a plena participação e igualdade de oportunidades para a mulher poder atuar na promoção do desenvolvimento sustentável. Além de se garantir um direito humano fundamental, esse empoderamento é visto como base necessária para se construir um mundo mais pacífico, próspero e sustentável (ONU, 2015).

Alerta-se aqui para a luta emancipatória das mulheres indígenas, sujeitas a múltiplas formas de violência e discriminação. Elas estão integram as populações tradicionais na América Latina que, segundo Pacheco (2017), enfrentam problemas específicos para o desenvolvimento sustentável e se esforçam para sair da invisibilidade. De acordo com o depoimento dos membros do Conselho Nacional de Mulheres Indígenas (Conami, 2006), essemovimento feminino vem ocorrendo desde 1996, embora tenha ganhado visibilidade só muito recentemente.Em 2017, dez anos após a assinatura da Declaração sobre os Direitos dos Povos Indígenas pelas Nações Unidas, a Comissão sobre o Status da Mulher (CSW) levantou a questão do empoderamento das mulheres indígenas.Em 2018, a ONU em parceria com a Embaixada da Noruega implementou o projeto "Voz das Mulheres Indígenas”, com o objetivo de estimular a mobilização social e de fortalecer a participação política dessas mulheres em diferentes grupos étnicos no Brasil. Esse projeto emergiu da iniciativa de coleta de informações em comunidades indígenas em todo o país, realizada pelas próprias lideranças femininas.

Mato Grosso do Sul é considerado, de acordo com dados do censo do IBGE de 2010, o estado com a segunda maior população indígena (73.295 indivíduos) do país (total de 817.962 indígenas). Nele, as mulheres das etnias Kaiowá e Guarani vem ganhando destaque, por suasrecentes práticas estratégicas de emancipação feminina. Zimmerman e Viana (2014) já haviam confirmado em seus estudos realizados em dois aldeamentos de Amambai em Mato Grosso do Sul, que as mulheres indígenas Kaiowá e Guarani encontravam-se entre as mais gravemente afetadas por violências múltiplas,desde 2007.

Entre os movimentos dessa natureza, passou a ganhar grande visibilidade as estratégias de luta pelo empoderamento das mulheres Kaiowá e Guarani a partir da Reserva Indígena de Dourados, o que motivou a atenção para essa pesquisa.

A questão feita e que norteou o encaminhamento dos estudos foi "em que níveis de poder estão ocorrendoasestratégias de lutas das mulheres Kaiowá e Guarani da Reserva Indígena de Dourados, nas condições específicas dadas pelo contexto no qual elas se manifestam?”.

A luta pelo empoderamento feminino na América Latina, segundo Sardenberg (2010),no seu início, voltou-se praticamente para a redução da desigualdade de gênero e contra a opressão masculina nas sociedades patriarcais. No Brasil, manifestaram-se duas modalidades de empoderamento feminino: o liberal e a emancipação libertadora. Na primeiramodalidade, o movimento tem sido mais de interesse individualista, marcado por 
ações com ideais liberais, de caráter mais racional. Já a "emancipação libertadora” tem sidoaquela de natureza mais coletiva, na busca de autonomia e determinação contra o patriarcado, embora o empoderamento pessoal não seja ignorado (Sardenberg, 2010).

No entanto, nas sociedades minoritárias na América Latina, a abordagem de práticas emancipatórias vêm sendo interpretadas, por Zibechi (2015), como lutas de resistência, fruto de um novo desafio civilizatório. Elas se manifestam, em acordo à lógica de cada comunidade, no sentido de serecriar o próprio modo de vida.Os adeptos do pensamento descolonialfazem uma crítica severa àqueles que analisam essas dinâmicas com uma abordagem do discurso homogêneo, de natureza eurocêntrica ou colonizadora (Escobar, 2003). Frantz Fanon (1968), um importante adepto desse pensamento na América Latina, preferiu interpretar a modernidade a partir do lugar do sujeito colonizado. Entre os elementos resgatados das teorias pós-coloniais, segundo SchererWarren (2010), também está a busca da complexidade simbólica e de orientação política, baseada no princípio da diversidade sociocultural. Nesse caso, a interpretação do movimento volta-se para um dos múltiplos aspectos em que pode se manifestar as lutas, entre outras a de natureza étnica e a de gênero.

Na “Declaração de San José” de 1981 (Unesco, 1981, p. 1), resultante da reunião internacional entre Unesco e Clacso, na qual foi denunciado o etnocídio e reivindicado o etnodesenvolvimento como um direito dos povos indígenas e dever dos Estados Nacionais, este foi definido como sendo:

“...ampliação e consolidação no âmbito da própria cultura, mediante fortalecimento da capacidade autônoma de decisão de uma sociedade culturalmente diferenciada, para conduzir seu próprio desenvolvimento e exercício de autodeterminação, em qualquer nível, mediante uma organização equitativa e própria de poder.Isto significa que o grupo étnico é a unidade político-administrativa com autoridade sobre seu próprio território e com capacidade de decisão relacionados a seus projetos de desenvolvimento, num processo de crescente autonomia e gestão" (tradução dos autores).

Entre os teóricos do etnodesenvolvimento, está Paul Little (2002), que valoriza nesse processo o reconhecimento da diversidade cultural e étnica em cada Estado Nacional latino-americano.O autor corrobora com a declaração de San José, ao considerar que amelhor escala para o etnodesenvolvimento é a do próprio territóriode cada grupo étnico. Esse processo supõe umesforço coletivo do grupo social para ocupar, usar, controlar e identificar-se com uma parte específica de seu ambiente biofísico. Como sua manifestação ainda depende de contingências históricas, existem muitos tipos de territórios, cada um com sua particularidade.cada grupo social mantém vínculos afetivos e de identidade, além deuma relação particular com a cosmografia, conhecimentos e ideologias, como também uma forma específica de uso social e defesa de seu próprio território (Little, 2002).

Bobbio (2004) vê na resistência à opressão, um direito humano. Segundo ele, ainda que esse direito não apareça explicitamente na Declaração Universal dos Direitos Humanos em 1948, em seu preâmbulo, está escrito que os direitos do homem devem ser protegidos, para evitar que ele seja forçado como último recurso, a praticar rebelião contra a tirania e a opressão. O fenômeno da resistência à opressão hoje é muito mais coletivo e significa um conjunto de comportamentos para mostrar ao oponente, que não pretende derrotá-lo e sim escolher uma maneira melhor de viver, da qual o próprio oponente possa se beneficiar.

O Banco Mundial (2002), ao levar em conta o informe sobre o Desenvolvimento Mundial de 2001, fez uso do conceito "empoderamento" por considerá-loum componente estratégico para reduzir a pobreza e fortalecer grupos excluídos. Este foi entendido, por essa instituição, como um processo, conduzido tanto por homens como mulheres, de incremento do acesso e controle dos recursos e das decisões, envolvendo a troca da natureza nas relações mantidas com atores governamentais e não-governamentais. Isso significa mudança nas regras, normas e comportamentos no contato com esses atores, que permitam dar voz a esses grupos, no que se diz respeito às suas vidas. Esseprocesso de empoderamentoatinge o nível familiar, comunitário, nacional e internacional, com impacto também no nível individual. (Banco Mundial, 2002).

De acordo com os membros do Action Aid (2012), a desigualdade da mulher pode ser verificada em diferentes níveis de domínios de poder: (1) nível social, considerado o domínio público do poder, cujas 
intervenções se manifestam através de instituições, leis, políticas e práticas de apoio e promoção; (2) nível comunitário, no qual as normas, valores e práticas sociais e culturais podem promover ou obstruir a desigualdade de gênero; 3) nível familiar,ou nível privado da família, que envolve relacionamentos com o casamento ou com o parceiro; (4) nível individual, ou nível íntimo de poder de cada mulher, capaz de atribuir mais autoconfiança, conhecimento e autoconsciência.

Segundo alguns estudos já realizados, as maiores dificuldades relacionadas ao etnodesenvolvimento latino-americano têm sido detectadas nas lutas conduzidas por mulheres indígenas. Pode-se citar, nesse caso, a obra publicada,sob organização da pesquisadora Diana Vinding em 1998, oumais o artigo de Sarah Radcliffepublicado em 2014. Pode-se deduzir, por meio dos casos analisados, que as mulheres indígenas vêm sofrendo processos de discriminação e marginalização, especialmente por ser mulher, pobre e indígena.

\section{Materiais e métodos}

Essa pesquisa teve como objetivo a realização de um estudo etnográfico junto às mulheres indígenas envolvidas nas lutas de emancipaçãona Reserva Indígena de Dourados, no Mato Grosso do Sul / Brasil, procurandointerpretar por meio de sua percepção, os níveis de poder que vêm se tornando foco de suas estratégias de lutas.

As Comunidades Kaiowá e Guarani das aldeias de Jaguapiru e Bororo, na Reserva Indígena de Dourados, estado de Mato Grosso do Sul, Brasil constituíram o objeto da pesquisa. Os sujeitos da pesquisa são as mulheres que protagonizam tais movimentos de resistência a partir dessa reserva, num processo de empoderamento feminino.

Como fontes secundárias, além de revisão bibliográfica, lançou-se mão de dados estatísticos e cartográficos. Os dados primários foram coletados junto aos sujeitos da pesquisa diretamente na aldeia, com apoio de questionários e entrevistas semiestruturadas, mediante termo de consentimento livre e esclarecido assinado pelos participantes.Por meio do questionário se obteve a identificação do perfil das lideranças femininas. A primeira entrevista semiestruturada foi aplicada a um grupo focal de onze mulheres, em uma roda de conversa, que favoreceu maior proximidade do cotidiano vivido por elas na aldeia.Foram aplicadas posteriormente entrevistas semiestruturadas às lideranças femininas, entrevistas individuais semiestruturadas com questões mais detalhadas.

Os dados das fontes secundárias foram organizados, de modo a melhor compreender o contexto territorial no qual emergiram as lutas resistência, que vêm contribuindo para o empoderamento das mulheres Kaiowá e Guarani. As falas obtidas por meio de entrevistas semiestruturadas (grupo focal e individuais) foram transcritas na íntegra, para sereminterpretadas a partir de categorias pré-estabelecidas.

\section{Discussão dos resultados}

As estratégias de luta de emancipação, organizadas pelas lideranças femininas, a partir da Reserva Indígena de Dourados, como se pode apreciar, enquadram-se na categoria de “emancipação libertadora” de Sardenberg (2010), como uma luta de natureza coletiva, ainda que os aspectos pessoais não sejam ignorados. Como integrantes de sociedades minoritárias em busca de maior autonomia, essas lutas também se expressam como resistência, num processo de recriação de seu próprio modo de vida.Por se tratar de um objeto de pesquisa de natureza complexa, optou-se avaliá-la no contexto histórico e espacial no qual a luta se manifesta.

\section{Kaiowá e guarani no contexto latinoamericano, brasileiro e de Mato Grosso do Sul}

O processo de colonização da América Latina, conforme aponta Aguilera Urquiza (2016), contribuiu, não só para o desaparecimento de muitos grupos indígenas, como parte deles foi sendo absorvido na sociedade dos colonizadores, ou então submetido a situações de violência.De acordo com oRelatórioda Cepal,apresentado 
à ONU em 2014,os 826 grupos indígenas na América Latina existentes em 2010 representavam apenas 8\% da população desse continente, sendo que $17 \%$ deles viviam em extrema pobreza. O maior número de indígenas estava no Brasil, Colômbia, Peru e México, embora sob risco de desaparecimento.No início da colonização portuguesa, a população indígena no Brasil foi estimada entre 2 a 4 milhões de habitantes indígenas (Funai, 2018), mas até a década de 1970, a população já havia sido reduzidaem 70 mil habitantes.

O Serviço de Proteção aos Índios (SPI) foi o primeiro órgão do governo federal, criado no Brasil em 1910,para prestar assistência às populações indígenas, serviçoaté então realizado somente por organizações religiosas. O trabalho mais importante desse órgão foi o de confinar uma grande parte desses povos em reservas indígenas. Em 1967, ele foi transformado em Fundação Nacional do Índio (Funai), com a finalidade de coordenar e gerir as políticas públicas federais de proteção dos direitos indígenas. Passaram a fazer parte de suas atribuições, os estudos de identificação e delimitação, demarcação, regularização fundiária e cadastramento de terras tradicionalmente ocupadas por povos indígenas, bem como o monitoramento dessas terras.Nas décadas seguintes, o país conheceu um processo de recuperação demográfica, que se acelerou especialmente no final do século XX e início do século XXI.Em 2010, de acordo com o censo oficial do IBGE, o Brasil já abrigava817.962 habitantes indígenas, o que significou um crescimento de 205\% em relação a 1991. Mesmo assim, esse contingente não representa mais do que0,4\% da população total do país. Pelo mesmo mesmo Censo de 2010, pôde-se constatar que as terras indígenas ocupavam 13,8\% da área brasileira, basicamente 98,25\% concentrada na Amazônia (ISA, 2018).A Constituição Federal Brasileira de 1988, nos artigos 231 e 232, reconheceu os direitos dos povos indígenas e a necessidade de proteger sua cultura, língua, costumes, tradições e territórios tradicionais, assim como a necessidade do governo brasileiro de garantir o respeito por suas propriedades. No entanto, são muitas as comunidades que ainda aguardam pela restituição de suas terras (Aguilera Urquiza, 2016).

Mato Grosso do Sul é o estado coma segunda maior população indígena do Brasil, ou seja,73.295 mil pessoas (IBGE, 2010), oque significa menos de dez por cento de sua população.Os principais povos indígenas presentesem Mato Grosso do Sul são: Kaiowá, Guarani (Ñandeva), Terena, Kadiwéu, Guató, Ofaié, Kinikinau, Atikum e Camba (Aguilera Urquiza, 2016).

A comunidade indígena mais numerosa é constituída pelosGuarani (Kaiowá e Ñandeva), estimadaem49.047 pessoas (IBGE, 2017). Tanto os Kaiowá quanto os Guarani pertencem à família linguística tupi-guarani, cujos grupos estão presentestambém noSul e litoral do país, no Paraguai, Bolívia e Norte da Argentina, considerados um dos povos indígenas com maior presença territorial nos países latino americanos (Grunberg, Pereira y Colman, 2016). No Brasil estão divididos em três grupos - Ñandeva, M’bya e Kaiowá com uma população de aproximadamente 85 mil pessoas, a grande maioria localizada em Mato Grosso do Sul.

Em Mato Grosso do Sul, os Kaiowá e Guarani originalmente encontravam-se na região do Itatim (Aguilera Urquiza, 2016), cujos primeiros contatos com os colonizadores ocorreramem 1530 (Chamorro e Combés, 2015). O período de atuação da grande empresa ervateira, a Companhia Mate Larangeira,após o conflito armado entre o Brasil e Paraguai (1864-1870) até o início do século XX, conformelembra Chamorro (2015), contribuiu para uma grande desordem social desses povos Kaiowá e Guarani. Nesse período, grande parte deles foi submetido a trabalhos forçados por essa empresa.

Entre 1915 e 1928, ocorreu a iniciativa governamental de confinamento de grande parte dos indígenas em oito reservas dentro do estado, pelo Serviço de Proteção aos Índios (SPI).A Reserva Indígena de Dourados constitui uma das oito reservas indígenas demarcadas nessa época, na vigência doDecreto Nacional 401, de 1917, para abrigar inicialmente 3.600 habitantes da etnia Kaiowá (Cavalcante, 2013). Aos poucos, essa reserva foi sendo transformada em área de inserção de novas famílias indígenasde outras etnias, incluindo entre elas, representantes das etnias Guarani (Ñandeva), Terena e outras (Mota, 2011). Para evitar os conflitos étnicos, na década de 1970 a reserva acabou sendo dividida em duas aldeias: Jaguapirú e Bororó (Nascimento, 2017).

Nas décadas de 1960 e 1970, o avanço da fronteira de modernização agrícola no Mato Grosso do Sul, com abertura de novas fazendasagrícolas, atingiu antigos territórios indígenas (Chamorro, 2015). O confinamento em reservas, segundo Brand (1997) e Aguilera Urquiza (2016), em princípio havia proporcionado condições para que os Kaiowá e Guarani conseguissem se manter com suas práticas tradicionais. Com o tempo, a aglutinação 
e o crescimento populacional ocorrido em espaços limitados das reservas indígenas, tornou esses lugares muito difíceis de se viver (Chamorro, 2015). Em função disso, muitas das famílias Kaiowá e Guarani começaram a abandonar esses espaços confinados,tentando se reaproximar de suas terras de origem (Pereira, 2007), ao mesmo tempo em que se sujeitam a trabalhar como mão-de-obra barata em fazendas agrícolas para poder sobreviver (Brand, 1997). Essas novas circunstâncias, por outro lado,também criam situações de confrontoviolento direto com agricultores das fazendas(Nascimento eBrand, 2006, citado por Aguilera Urquiza, 2016).

Como consequência desse processo,vêm ocorrendo a desestruturação dessas comunidades do ponto de vista social e cultural (Aguilera Urquiza, 2016). Conforme assinala esse autor, surgiram problemas graves, como alcoolismo, altas taxas de desnutrição, prostituição, tuberculose, suicídio, violência interna, imposição de líderes na aldeia, reorganização da organização familiar, novas crenças religiosas substituindo a tradicional, tornando ineficaz a prática dobem viver desses povos. Por seu turno, o alcoolismo, consumo e tráfico de drogas passaram a contribuir parapromover violência também entre as unidades sociais dentro das reservas, levando muitas famílias a acampar em beira de estradas (CIMI, 2011).

A luta de resistência dosKaiowá e Guarani no Mato Grosso do Sul passou a se manifestar com maior ênfase, a partir de 1978, na requisição à Funai de parte de sua terra original (Chamorro, 2015). Para esses povos, isso significa o retorno ao Tekoa, lugar onde possam reproduzir sua existência e estilo de vida, realizar seus rituais, músicas e danças (Brand, 1997).Essas lutas também envolvem denúncias aos organismos nacionais e internacionais acerca desse processo histórico de espoliação de suas vidas. A Constituição Federal de 1988, a Convenção 169 sobre Povos Indígenas e Tribais da Organização Internacional do Trabalho (OIT) de 1989, o Ministério Público Federal e as políticas públicas de inclusão social (Chamorro, 2015) vieram trazer maior reforço a essa luta.Com base no direito garantido pela Constituição Federal, o grupo Kaiowá e Guarani,a partir da década de 1980, passou a organizar periodicamente uma grande assembleia, nominada Aty Guasu. Seu objetivo é possibilitar a identificação de problemas comuns e sugerir ações coletivas de reivindicação perante o Estado brasileiro.

Em 2018, segundo o Instituto Socioambiental ISA, aReserva Indígena de Douradosjá contava com 15.023 habitantes, portanto, mais de quatro vezes o total inicial nela confinado, incluindo grupos de outras etnias e nãoindígenas (Cavalcante, 2013). Encontram-se, conforme alerta Nascimento (2017), imersos em um ambiente precário, marcado pela miséria, pelo medo e pela tensão cotidiana geradas pela violência.

As aldeias Bororo e Jaguapiru apresentam características particulares, mas interagem entre si, especialmente os Kaiowá e Guarani, em função da similaridade de suas culturas. A aldeia Bororo concentra um maior número de famíliasKaiowá e Guarani. Além disso, possui área mais extensa e menos populosa,também de mais difícil acesso e que apresenta maior situação de pobreza (Mota, 2011). Nela, aparece apenas um pequeno número de indígenas Terena, assim como Bororo e Kaingang (DSEI, 2017). A língua predominante é o guarani e seus habitantes exibem um modo de vida mais ligado às suas tradições. Tem sido a aldeia mais sujeita a problemas sociais, saúde, mortalidade infantil e educação (Nascimento, 2017). Já na aldeia Jaguapiru predomina a população Guarani, Kaiowá e Terena, com maior número dessa última etnia, além de Kadiweu e nãoindígenas (DSEI, 2017). Ainda que de área menor, seus moradores contam com mais vias de acesso e estão mais próximos da rodovia, além de suas casas serem servidas de eletricidade e água (Passos, 2007).O número de jovens que estudam fora e se casam com não-indígenas tem sido mais crescente, motivo que explica o fato de Jaguapiru estar mais impregnada da cultura não indígena (Nascimento, 2017).

Na organização social dosKaiowá e Guarani a reprodução da vida comunitária e a base da sociabilidade estão nas relações familiares, ou de parentesco, suas unidades sociais (CIMI, 2011). Tais unidades funcionam de forma autônoma, no que se diz respeito à sua territorialidade, sistema político e econômico, com lideranças próprias, tanto civis como religiosas. Nesse contexto, as mulheres Kaiowá e Guarani assumem uma série de responsabilidades na ordem coletiva e parental, traçando novos caminhos e fortalecendo a reprodução da vida social (Seraguza, 2013).

As novas condições vividas na reserva e o trabalho temporário dos homens fora dela, segundo Zimmerman, Souza e Alves Viana (2014), redefinem as relações de gênero no âmbito da unidade social, muitas vezes tornan- 
do-as conflituosas. Desse modo, asmulheres Kaiowá e Guarani da Reserva Indígena de Dourados têm sido vítimas de ações violentas, não só da sociedade não-indígena fora da aldeia,como no contexto de sua própria comunidadedentro da reserva (Pacheco, 2017).

\section{Estratégias de luta pelo empoderamento das mulheres Kaiowá e Guarani na Reserva Indígena de Dourados}

As estratégias de luta de emancipação, organizadas pelas lideranças femininas, a partir da Reserva Indígena de Dourados, como se pode apreciar, enquadram-se na categoria de “emancipação libertadora” de Sardenberg (2010). Trata-se, portanto, de uma luta de natureza mais coletiva, ainda que os aspectos pessoais não sejam ignorados e por ser de natureza complexa, precisa ser avaliada no contexto no qual se manifesta. Conforme afirmou a presidente do Conselho Nacional da Mulher Indígena (Conami, 2006), essas mulheres indígenas Kaiowá e Guarani vem deixando o anonimato para buscar coragem e força para lutar e transformar suas realidades. Essas manifestações de resistências múltiplas contra muitas opressões, de acordo com Puigros (2016),fazem parte de um feminismo indígena, que não coaduna com as lutas do feminismo ocidental. O empoderamento é uma forma de buscar o próprio modo de fazer e viver,em acordo àspróprias crenças,num contexto de descolonização e contra a modernidade hegemônica (Puigros, 2016).

Importante salientar que, embora esse movimento liderado por mulheres Kaiowá e Guarani tenha emergido dentro da Reserva Indígena de Dourados, ele já expandiu para a região. Foi possível verificar que, dentre as 21 lideranças consultadas, 57,1\% nasceram e moram nas aldeias de Jaguapirú e Bororo, enquanto 42,9\% nasceram e moram em Dourados e aldeias da região. Ainda que existam lideranças de várias faixas etárias, a população adulta representa a grande maioria (72\%), isto é, mulheres com 18 a 55 anos de idade. Entre essas, 28\% desempenham apenas funções domésticas, enquanto outras $14 \%$ são rezadeiras. As $34 \%$ de jovens estudantes, que trabalham fora da aldeia são predominantemente de origem Terena. De acordo com o perfil de escolaridade apresentado pelas entrevistadas, mais da metade delas (51,38\%\%) conta apenas o ensino fundamental (completo e incompleto) e $19,04 \%$ delas com ensino médio (completo e incompleto) e 4,76\% analfabetas. Chamou atenção, no entanto, o fato de 23, 31\% das lideranças estarem frequentando a universidade e mesmo a pósgraduação. Do total pesquisado, 40,62\% eram casadas, 38,10\% solteiras, 4,76\% separadas e 9,52\% em outras condições. De acordo com a percepção das entrevistadas, para ser líder um dos critérios é a relação de confiança.

“A idade não importa para ser líder. Pode ser jovem, pode ser velha. O importante é a confiança, sabendo que elasestejam trabalhando pelos direitos de todos”(Entrevistada 1, 17 de maio de 2018).

Na visão das lideranças, a diferença entre os moradores de Jaguapirú e Bororo também afeta o movimento de empoderamento das mulheres. Na aldeia de Bororo, as mulheres Kaiowá-Guarani estão mais engajadas na participação das reuniões na aldeia Bororo porque a maioria delas não estuda nem trabalha fora da aldeia. Na aldeia de Jaguapirú, a maioria das mulheres indígenas trabalha e estuda, mas elas são mais organizadoras do movimento feminino. Eles participam menos do encontro dentro da Vila Jaguapirú.

“Aqui em Bororo as mulheres Guarani e Kaiowá são predominantes. Lá no Jaguapirú a maioria é Terena. Aqui em Bororo, as mulheres participam mais das atividades que envolvem a comunidade, principalmente em saúde. Em Jaguapirú muitas mulheres de lá trabalham fora” (Entrevistada 14, 2 de junho de 2018).

\section{Estratégia pelo empoderamento feminino no nível da comunidade indígena}

As mulheres Guarani e Kaiowá, conforme assinala Seraguza (2013), sempre assumiram responsabilidades na ordem do coletivo indígena e da parentela ou família extensa. No entanto, a parentela perdeu muitas de suas atribuiçõeseconômicas, políticas, festivas e rituais anteriores, embora ainda caiba à mulher o papel de unir e alimentar seus integrantes (Pereira, 2008).

No nível da comunidade indígena, as lideranças femininas entrevistadas reconhecem o papel importante que ainda exercem na manutenção das aldeias, nas atuais condições vividas. Ela se torna mais fundamental, na 
atual condição em que os homens permanecem mais tempo fora delas. Essa nova condiçãotem impactado a estrutura e o modo de vida tradicional dessa comunidade, assim como a maneira tradicional de viver em família.

Na fala das entrevistadas, a mulher tem sido importante detentora do conhecimento Kaiowá e Guarani dentro da aldeia, especialmente as mulheres mais idosas. Mas elas procuram também se alimentar do conhecimento obtido fora da aldeia, nesse caso, trazido quase sempre pelas mais jovens.

"Eu acho que a idade não é importante para ser um líder. Mas é claro que as mulheres mais velhas têm mais conhecimento sobre nossa cultura e mais experiências que mulheres mais jovens. Os mais jovens possuem conhecimento tecnológico, que também contribui”(Entrevistada 14, 2 de junho de 2018).

Entre as mulheres que detém conhecimentos nas aldeias, o destaque foi dado às rezadeiras (Ñandesi), artesãs, professoras e agentes de saúde.

“Nós, mulheres Guarani Kaiowá, somos importantes porque carregamos a cultura. Nós fazemos artesanato. Nós somos mulheres rezadeiras, Ñandesi. [...]Nós não podemos perder nossa cultura, porque se a perdermos, perdemos a nossa terra”(Entrevistada 21, 14 de junho de 2018).

"Os agentes de saúde, quando falam, têm atitude de liderança por causa do conhecimento que possuem na área. Na educação, professores e algumas mulheres que praticam atividades da cultura tradicional”(Entrevistada 14, 2 de junho de 2018).

Na visão dessas lideranças, entre as mulheres da aldeia, as mais respeitadas pelos homens têm sido as mais idosas, como também as rezadeiras Ñandesi (xamãs) e as agentes de saúde. “....as mulheres mais velhas são as que mais eles respeitam, porque são elas que dominam a família, lideram a organização das coisas para fazêlas acontecer.” (Entrevistada 20, 13 de junho de 2018). Já como agente de saúde “eles nos valorizam, quando damos um monte de números, bons números”.(Entrevistada 17, 3 de junho de 2018).

Ainda no nível da comunidade indígena, as lutas femininas têm sido organizadas para a reivindicação de serviços que dependem de políticas e intervenções de domínio público. Na percepção das lideranças, elas devem continuar a luta dos antepassados pelos seus direitos, de modo a garantir um futuro melhor para sua comunidade.

“O papel de líder é administrar a aldeia e trazer melhorias para seus povos. Hoje eu estou aqui no movimento por meu avô que lutou pela terra, minha tia que também morreu. [...] Esses são os exemplos que tenho, e estou seguindo” (Entrevistada 20, 13 de junho de 2018).

“As mulheres líderes sempre lutam pela comunidade. [...]Elas têm que estar por trás e conhecer o que é necessário, ver o que está faltando, seja na educação, esportes, alimentação, agricultura familiar, várias coisas”(Entrevistada 8, 14 de junho de 2018).

“Estou motivado para ser líder na busca pelos direitos dos povos indígenas, por toda a saúde indígena, pela educação no território. [...] Tudo o que vem para ajudar a comunidade, então, isso me motiva a estar sempre envolvida na situação de jovens, mulheres, crianças e também trabalhar dia a dia” (Entrevistada 14, 2 de junho de 2018).

Uma outra forma de luta feminina levada ao nível da comunidade indígena, tem sido a do apoio aos homens, nas estratégias estabelecidas pela reconquista de seus territórios tradicionais. Elas revelam por meio de seus discursos que, como estão cientes de seu papel central exercido no âmbito da família e da comunidade, acreditam que os homens só se fortalecerão se elas estiverem juntas. No entanto, reconhecem que as decisões finais ainda acabam sendo tomadas pelos homens da aldeia. Acreditam que podem mudar essa situação.

“A mulher indígena é a base de toda família. É ela quem tem todo o controle da casa, da família, da própria comunidade. Muitas das coisas começam por elas. Embora os homens sejam líderes, as coisas 
sempre acontecem com a ajuda delas. As mulheres estão ajudando ou indo para a frente da situação"(Entrevistada 14, 2 de junho de 2018).

"As mulheres participam, mas muitos homens ainda falam pelas mulheres. Este é um processo. Às vezes, até no encontro de mulheres acaba sendo o homem que está dirigindo. Termina que a presença masculina está sempre lá. É sempre predominante. [...] as mulheres são protagonistas nas tomadas de decisão, mas esta acaba sendo definida e conduzida pelos homens”(Entrevistada 14, 2 de junho de 2018).

Elas também acreditam na força da solidariedade feminina,assim como na capacidade de ensinar e aprender juntas.

“A indígena hoje é muito importante porque ela está levando a voz principalmente na recuperação de suas terras e na educação de seus filhos. No passado, as mulheres costumavam não ter espaço na perspectiva masculina do machismo.[...] Atualmente, as mulheres já ocupam espaço, já disputam seus direitos, defendem seus direitos.[...] As mulheres já são mais livres, não totalmente, mas isso já está mudando" (Entrevistada 20, 13 de junho de 2018).

"Mulheres de outras aldeias são convidadas principalmente para a recuperação da terra.[...] Mas também são convidados a compartilhar suas experiências sobre o que pretendem fazer lá. Há convidados de outros lugares em outros para aprender a fazer as coisas, transformar ideias e experiências" (Entrevistada 21, 14 de junho de 2018).

"Quando nos reunimos as pessoas conversam, ensinam quem não sabe. Quem mais conhece ajuda quem não sabe”(Entrevistada 1, 17 de maio de 2018).

"Eu preciso é compartilhar o que estou aprendendo. [...] eu tenho que compartilhar com mulheres que não são líderes e fazê-las acreditar na luta. precisamos compartilhar com elas o que estou aprendendo, e vou aprender ainda mais” (Entrevistada 8, 14 de junho de 2018).

As lideranças femininas reconhecem o desafio em estabelecer o mesmo processo de aprendizagem com os homens da aldeia.

"Se as mulheres vierem aprender com elas, os homens também devem vir. Os homens que têm um bom diálogo e atitude para ajudar as mulheres, ganham respeito na troca de conhecimentos” (Entrevistada 5, 17 de maio de 2018).

Segundo as lideranças femininas, ainda há muitos outros desafios a serem enfrentados na manutenção desse movimento de emancipação coletiva. Mesmo que já tenham voz, nem sempre são ouvidas e muitas vezes são desencorajadas para esse propósito.

\section{Estratégia pelo empoderamento feminino no nível familiar}

Estudos anteriores, como os de Seraguza (2013), já apontavam que na situação original, a divisão familiar de tarefas entre homens e mulheres eram complementares, sem que a mulher se sentisse subjugada. Portanto, inexistiam conflitos de gênero no âmbito da família. No entanto, conforme assinala Pereira (2008), as reservas mais povoadas, como a de Dourados, enfrentam problemas organizacionais, frente ao alto índice de problemas sociais, que dificultam o seu controle.Os homens são os que mai saem para trabalhar fora. Nesse conjunto de mudanças relacionadas à ordem da aldeia, a família também tem sido atingida.

As mudanças na aldeia, segundo as entrevistadas, também vêm contribuindo para transformar a parentela num modelo de família nuclear. Como os homens se retiram para trabalhar, as mulheres atuam praticamente sozinhasna transmissão da cultura e tradições dentro da aldeia. Elas revelam a luta pelo respeito dos homens em função desse papel exercido. 
“Hoje nas famílias daqui da aldeia não temos mais a figura da família extensa. Então, na família nuclear é predominante apenas com o pai, a mãe e os filhos. Muitas vezes, termina que ela está sem marido, ou é uma mulher sozinha ou solteira. [...] agora é apenas a mãe, o pai e os filhos, ou apenas mãe e filhos, ou apenas pai e algumas filhas, o pai separado e já num segundo casamento. A mãe está no terceiro casamento e já teve filhos. É um processo assim” (Entrevistada 14, 2 de junho de 2018).

"Sem a força das mulheres, as famílias são deixadas sozinhas. .[...] A mulher garante a família. Os homens têm que respeitar”(Entrevistada 16, 2 de junho de 2018).

Na atual conjuntura, no nível da família indígena, as mulheres se sentem mais vulneráveis, discriminadas e desvalorizadas pelos homens e lutam por se emancipar. Ainda que estejam conscientes da importância de seu papel na manutenção da família, elas se ressentem da discriminação e falta de apoio masculino, seja para poder estudar ou trabalhar fora da aldeia. Quando questionadasna Roda de Conversa, sobre o reconhecimento do papel das mulheres na Reserva Indígena de Dourados, a grande maioria (80\%) respondeu positivamente. No entanto, durante as entrevistas semiestruturadas individuais, elas acabaram revelando que são alvos de preconceito no âmbito familiar.

"Há muito preconceito na comunidade. [...] tem muita discriminação por parte dos homens. [...] Muitas mulheres não são valorizadas. Eles não conseguem trabalhar para poder cuidar da família. É daí que vem a situação, elas não estudam, sendo difícil encontrar apoio financeiro para poder estudar” (Entrevistada 14, 2 de junho de 2018).

Também se reportaram à situação de inferioridade e discriminação masculina que enfrentam, em casos de separação.

“Agora, as mulheres não são valorizadas por muitas razões. Por exemplo, quando se separam, o homem fica com a casa e com as crianças. E em muitos casos, elas deixam tudo em casa e só saem com as crianças e as roupas. Os homens dizem que foi a mulher quem deixou a casa e quem perdeu foi ela” (Entrevistada 17, 3 de junho de 2018).

Pode-se verificar que as estratégias da luta feminina, no nível da família, tem sido, para por fim à situação de inferioridade a que vem sendo submetida em relação ao homem, ao reconhecimento de seu papel exercido na manutenção familiar e por maior autonomia na definição de sua vida profissional.

\section{Luta pelo empoderamento feminino no nível social fora da aldeia}

As mulheres Kaiowá e Guarani da Reserva Indígena de Dourados também enfrentam desafio maior do que os homens,no nível social fora da aldeia, não só porque são indígenas e pobres, mas ainda por serem mulheres. O esforço delas tem sido muito maior para enfrentar, tanto problemas de natureza discriminatória, como as ameaças dos donos de terras.

Uma das estratégias apontadas pelas lideranças femininastêm sido o enfrentamento de preconceitos por parte dos não-indígenas, num esforço para descolonizar o pensamento predominante nessa sociedade, quando pretende nela se estabelecer.

“Aqui em Dourados eu sei que eles são muito poucos valorizados no meu jeito de ver as coisas. Aqueles que são valorizados são apenas alguns que conseguem emprego” (Entrevistada 8, 14 de junho de 2018).

Para Zibechi (2015) descolonizar o pensamento exige criatividade para estabelecer seu próprio jeito de fazer e não imitar o colonizador. De fato, as mulheres Kaiowá-Guarani da Reserva Indígena de Dourados demonstram, por meio de suas falas, a força que precisam encontrar internamente para enfrentar o preconceito por parte dos não-indígenas.

“As mulheres indígenas estão passando por preconceitos ... Eu não tenho vergonha de falar sobre isso. 
[...] Os não-indígenas não querem falar de indígenas. Eles não querem saber nada sobre isso. Eles não querem ouvir você. Você tem que mostrar o peito, encará-los e orar" (Entrevistada 8, 14 de junho de 2018).

"Para nós mulheres indígenas, enfrentar a discriminação e preconceito constitui o maior desafio [...] Ser uma mulher indígena é difícil. Para suportar tudo o que as pessoas estão passando hoje em dia, é muito doloroso. Ainda mais quando você se levanta e fala em favor das mulheres e você leva um tapa dos nãoindígenas que você não imaginava”(Entrevistada 8, 14 de junho de 2018).

Elas se referem, em específico ao enfrentamento das ameaças dos donos de terras, no processo de luta pela recuperação de seus territórios de origem.

"Como mulher você tem que enfrentar as ameaças, fugir e fugir dos donos da terra, estar lá na terra recuperar pela força "Retomada” e ver seus filhos todos juntos. Isso é chocante”(Entrevistada 20, 13 de junho de 2018).

Um evento de destaque, organizado pelas mulheres Kaiowa-Guarani da Reserva Indígena de Dourados em 2012, nesse movimento reivindicativo dentro e fora da aldeia, tem sido a Assembléia das Mulheres Indígenas Aty Kuña. A finalidade foi construir um espaço de decisão na comunidade Kaiowa-Guarani, como também garantir maior representatividade na Assembleia Geral de Aty Guasu, onde somente os homens têm voz e voto. Elas ainda se servem dessa assembleia femininaparacapacitação e tomada de decisão nos fóruns e assembleias nacionais e internacionais dos quais já se tornaram participantes (O Progresso Digital Newsaper, 2017).

No início, as reuniões eram mais voltadas para se discutir o que estava acontecendo nas comunidades, o que era necessário melhorar e ações a serem tomadas, ao identificar a violação de seus direitos dentro e fora da aldeia. Fez parte dessa lista de reflexões a preservação da cultura Kaiowá-Guarani e a recuperação sua terra tradicional "Tekoha".

A fundadora da Assembleia “Aty Kuña”, a Xamã “Ñandesi” e a chefe Guarani afirmou:

"Se não falarmos quem vai falar por nós? [...] E isso começa a partir da casa, onde estamos no comando de tudo. Nos separamos dos homens e fazemos nossas próprias mulheres se encontrarem. Na primeira reunião, 470 mulheres participaram. Os homens não nos apoiaram, mas foram ver o que acontecia”(Entrevistada 13, 19 de maio de 2018).

A Assembleia das Mulheres Indígenas AtyKuña constitui um espaço para trocar experiências e falar sobre o tema da violação dos direitos das mulheres, uma vez que segundo as lideranças entrevistadas, não está sendo levada em conta na Grande AssembleiaAtyGuasu.

“A relação entre mulheres indígenas Guarani e Kaiowá geralmente é um pouco diferente da Assembleia Geral Aty Guasu. Por exemplo, os homens não discutem violência sexual na aldeia. Em nossa assembleia nós incluímos tudo isso”(Entrevistada 8, 14 de junho de 2018).

"Por exemplo, geralmente na Aty Guasu elas realmente não têm voz, e não podiam dizer o que queriam.[...] Eles não sabem falar sobreviolência contra as mulheres, porque o seu parceiro está lá, e ele é o líder”(Entrevistada 14, 2 de junho de 2018).

Além disso, a assembleia feminina da Aty Kuña está aberta para os homens que querem participar das reflexões e decisões, mas precisam aprender a respeitar a opinião das mulheres. A partir de 2016, as mulheres tambémconquistaram o direito à voz na Assembleia do Grande Kaiowá-Guarani Aty Guasu, de organização masculina.Segundo elas, essa participação feminina ainda é pequena, pois na tomada de decisões ainda não tem sido suficiente. 
"As mulheres têm voz em Aty Guasu, mas ainda é muito pouco. [...] Não é uma participação igual sempre. A participação masculina é mais forte” (Entrevistada 14, 2 de junho de 2018).

"Por exemplo, se as mulheres se levantam para conversar, elas ficam de prontidão e as ouvem. O comitê de mulheres está sempre junto. As vozes femininas que participam do movimento indígena no Brasil em geral são respeitadas dentro da Aty Guasu” (Entrevistada 8, 14 de junho de 2018).

Outro papel da “Aty Kuña” tem sido a capacitação das mulheres Kaiowá e Guarani,para tomada de decisões em reuniões nacionais e internacionais, fóruns, workshops e conferências, promovidas por organizações indígenas estaduais e organizações não-governamentais (Pacheco, 2017). Isso explica as parcerias já mantidascom diversas organizações, relacionadas a direitos humanos, movimentos sociais e universidades (O Progresso Digital Newsapaper, 2017).A presença da ONU na realização de uma Aty Kuña em 2018 expressa o compromisso já assumido por essa organização,para aprofundar o trabalho com mulheres indígenas e elaborar com elas um plano de emergência diante do agravamento da situação.

As demandas das mulheres indígenas não podem ser entendidas fora do quadro das lutas de seus povos pela autonomia, mediante novo relacionamento com o Estado, que lhes permita exercer controle sobre seus governos, territórios e recursos naturais. (Pacheco, 2017).

\section{Empoderamento feminino no nível individual}

Nesse movimento coletivo de lutas das mulheres indígenas Kaiowá e Guarani, dada a complexidade de relações que o mesmo implica, o empoderamento feminino, que se dá em nível pessoal, não se manifesta de forma independente, uma vez que esse processo é sistêmico, com mútuas interferências nesse campo interativo dentro e fora da aldeia. O empoderamento individual emerge, sobretudo, de um processo de conscientização e de experiências, construídos no ambiente de aprendizagem e de reflexões no âmbito do movimento. As expressões desse processo emancipativo se fizeram transparecer em diversas passagens das falas anteriormente apresentadas. De um lado, elas transpareceram em relação às competência construídas e aos sentimentos de autoestima, autoafirmação e autoconfiança, nas relações de poder, enfrentadas na família, comunidade e fora da reserva. De outro, observa-se que a percepção construída a respeito desse protagonismo tem contribuído para atitudes individuais de maior persistência e desinibição, na solução dos problemas coletivos, dos quais cada uma delas também se beneficia. Tudo isso pode ser traduzido em maior autonomia conquistada por cada uma coletivamente

\section{Considerações finais}

O empoderamento das mulheres Kaiowá e Guarani, que se manifesta na particularidade da Reserva Indígena de Dourados, como se pôde refletir nos dados obtidos pela pesquisa, revela-se como mais uma forma de prática de resistência indígenana América Latina, utilizada como um meio para se recriar o próprio modo de vida.

Do ponto de vista contextual, o trabalho reflete o novo momento demográfico e de postura descolonial dos povos indígenas, que tiveram seus direitos violados por longo tempo, num desrespeito à sua cultura e soberania sobre seus territórios. Apoiam-se para esse fim no etnodesenvolvimento, ou seja, no desenvolvimento concebido e operacionalizado em acordo à lógica própria de sua etnia, construída historicamente no território de origem.Como se pôde apreciar, é nesse contexto que as mulheres estão construindoestratégias para sua própria prática de emancipação, na forma de lutas de resistência, em função das experiências vividas em seu território particular. Entre outros, a perda histórica de suas terras, os conflitos com os novos ocupantes delas, a superlotação demográfica na situação de confinamento na reserva e as circunstâncias de discriminação e preconceito de gênero dentro e fora das aldeias constituíram importantes contributos para a manifestação desse movimento. Desse modo, a Reserva Indígena de Dourados foi transformada num território de resistência feminina, no qual se manifestam práticas de lutas comprometidas com um processo emancipatório de natureza mais complexa do que geralmente tem demonstrado os movimentos feministas não-indígenas. 
As práticas emancipatórias dessas lideranças femininas indígenas são consideradas complexas, na medida em que envolvem desde o interesse específico das mulheres em minorar as desigualdade de gênero, até aqueles de interesse mais geral, ligados ao modo de vida da comunidade na Reserva Indígena de Dourados e da sociedade indígena em geral, levando em conta as dimensões sociocultural, econômica e ambiental. Essa natureza complexa deempoderamento, conquistado por meio dessas lutas de resistência, manifesta-se em quatro níveis: (1) individual, por implicar emmaior autonomia individual das mulheres, conquistada coletivamente,em suas relações dentro e fora da aldeia; (2) familiar, uma vez que aemancipação feminina apresenta potencial para alterar as relações mantidas com os parceiros na vida privada dentro da aldeia; (3) comunitário, já que nesse processo as mulheres criam estratégias para ampliar coletivamente seus conhecimentos e competências profissionais, além do que o seu empoderamento junto aos homens as afirmam dentro da reserva nos processos de condução dos destinos da comunidade e de retomada dos territórios de origem; (4) social, pelo fato dasmulheres atingiram um nível de capacitação ede poder de organização, que já as habilitaram aconquistar níveis de participação em processos de decisão junto a organizações nacionais e internacionais, com reflexos nas sociedades indígenas nacionais e internacionais em geral.

É interessante observar nesse processo que, de um lado, as lideranças femininas justificam a retomada de suas terras e se reportam à necessidade de retorno ao Tekoha, para nele recriar o modo de vida próprio dos povos Kaiowá e Guarani. Nesse sentido, procuram manter os princípios dessa culturaétnica, mediante suporte das mulheres da aldeia que detém esses conhecimentos étnicos. O processo de emancipação, nesse caso, se dá em relação à cultura colonial, evidenciando-se uma consciênciadescolonial baseada no etnodesenvolvimento. Nesse caso, esse processo se dá basicamente por meio de práticas emancipatórias relacionadas com a retomada dos territórios de origem, num trabalho solidário àqueles já protagonizados anteriormente pelos homens dos povos Kaiowá e Guarani.

De outro lado, verifica-se a construção de práticas estratégicas relacionadas à redução da desigualdade de gênero e opressão masculina, vivenciadas tanto na cultura ocidental como na indígena. Nesse caso, as estratégias de resistência visando a emancipação feminina também se baseiam em princípios da cultura ocidental, tais como aqueles relacionados às táticas de se capacitar para o trabalho e escolarização fora da aldeia;ou então em relação à supremacia que os homens da aldeia tentam manter sobre elas. Revela um procedimento descolonial do tipo misto, apregoado por FrantzFanon (1963), em que se retira apenas as partes úteis do pensamento europeu, para adaptá-las à realidade e experiência vividas. Desse modo, compreende-se o perfil das mulheres que protagonizam essas práticas emancipatórias, por meio de lutas de resistência, baseadas muito mais nas competências construídas na cultura Kaiowá e Guarani, mas ao mesmo tempo complementadas por aquelas competências construídas na cultura não-indígena.

Nesse processo coletivo de reinvenção territorial visando maior sustentabilidade étnica, esse movimento feminino acaba sendo gerador de inovações criativas. Assim, por exemplo, ao construírem redes de cooperação feminina, geram-se espaços de diálogo que permitem, entre outros, compartilhar saberes e promover capacitação profissional. Como essas redes e suas assembleias não são fechadas aos homens, o que significa falta de confronto de gênero, essas práticas emancipatórias reúnem condições para efetivamente potencializar os movimentos descoloniais indígenas, que se manifestam no Brasil e continente latino-americano, por meio do etnodesenvolvimento.

\section{Agradecimentos}

Os autores agradecem ao Conselho Indigenista Missionário pelo apoio oferecido durante a realização da pesquisa.

\section{Bibliografia}

Action Aid, (2012).Theory of Change for Tackling Violence Against Women and GirlsGender\& Development Network, Inglaterra. Recuperado de www.actionaid.org.uk/sites/default/files/doc_lib/theory_of_change_on_v awg.pdf. 
Aguilera Urquiza, A.H. (2016).Antropologia e História dos Povos Indígenas em Mato Grosso do Sul. Campo Grande, Brasil: UFMS.

Banco Mundial (2002). Empoderamentar a los Pobres y Promover la Rendición de Cuentas em LAC. Buenos Aires, Argentina: Banco Mundial.

Bobbio, N.(2004). A era dos direitos. Rio de Janeiro, Brasil: Elsevier Editora Ltda.

Brand, A.(1997). O impacto da perda da terra sobre a tradição Kaiowaì/Guarani: os difíceis caminhos da palavra (Tesisdoctoral), Pontificia Universidade Católica do Rio Grande do Sul, Porto Alegre, Brasil.

Cavalcante, T. L. (2013).Colonialismo, território e territorialidade: a luta pela terra dos Guarani e Kaiowá em Mato Grosso do Sul. Assis, Brasil: Unesp.

Cepal/Eclac United Nations Economic Commission for Latin America and the Caribbean (2014). Guaranteeing Indigenous people's rights in Latin America. Santiago, Chile.

Chamorro, G. (2015). História Kaiowá:das origens aos desafios. São Bernardo do Campo, Brasil: Contemporâneos, Nhanduti.

Chamorro, G. yCombeìs, I. (2015).Povos indígenas em Mato Grosso do Sul: história, cultura e transformações sociais. Dourados, Brasil:UFGD.

Conselho Nacional de Mulheres Indígenas- Conami (2006). NatysenPo: trajetória e luta da mulheres indígenas. Presidente Mirian Marcos Tsibodowapreì(Apresentação.) Belo Horizonte, Brasil: FALE/ UFMG.

Conselho Indigenista Missionário- Cimi (2011).As violências contra os povos indígenas em Mato Grosso do Sul: e as resistências do bem viver por uma terra sem males- dados 2003-2010. Regional de Mato Grosso do Sul, Campo Grande, Brasil.

Dahl, G. yRabo, A. (1992).Kam-Ap or Take-Off: Local Notions of Development(Studies in Social Anthropology). Stockholm, Noruega: Stockholm University.

Denevan W. M. (1976).The Native Population of the Americas in 1492. Madison, EUA: University of Wisconsin.

Distrito Sanitários Especiais Indígenas- DSEI/ Mato Grosso do Sul (2017).População do DSEI Mato Grosso Do Sul -distribuídos por Municípios/UF, Polos Bases, Aldeias, e Etnias. Recuperado de http:// portalarquivos2.saude.gov.br/images/pdf/2017

Escobar, A. (2003). Mundos y conocimientos de otro modo: el programa de investigación de modernidad/colonialidad Latinoamericano.Tabula Rasa, (1)51-86. Recuperado de:www.ram-wan.net/restre- po/decolonial/1-escobartabula-rasa.pdf.

Fanon, F. (1968).Los Condenados de la Tierra. Ciudad de México, México:Fondo de Cultura Económica.

Fundação Nacional do Índio-Funai.(2018). Terras indígenas: o que eì? 2018. Recuperado de www.funai.gov.br/ index.php/nossas-acoes/demarcacao-de-terras- indigenas?limitstart=0\#.

Grunberg, G. Pereira, L.M y Colman, R. (2016).Mapa continental 2016. Conselho Indigenista MissionárioCimi/ Regional de MS. Campo Grande, Brasil.

Instituto Brasileiro de Geografia e Estatística -Ibge(2010). Características gerais dos indígenas: resultados do universo. Rio de Janeiro, Brasil: IBGE 
Instituto Brasileiro de Geografia e Estatística (IBGE). (2010) Censo Demográfico. Recuperado de: www.ibge.gov.br.

Little, P.(2002). Etnodesenvolvimento local: autonomia cultural na era do neoliberalismo global. Tellus, 2 (3), 33. doi:10.20435/tellus.v0i3.23

Mota, J.G.B.(2011).Territórios e territorialidades Guarani e Kaiowaì: da territorializac?abo precária na reserva indígena de Dourados à multiterritorial idade. Dissertação (Mestrado em Geografia). Universidade Federal da Grande Dourados, Dourados/MS.

Nações Unidas (2015). Objetivos do Desenvolvimento Sustentável. Transformando Nosso Mundo: a Agenda 2030 para o Desenvolvimento Sustentável. Recuperado de: https://nacoesunidas.org/wp-content/uploads/2015/ 10/agenda2030-pt-br.pdf

Nascimento, G. R. F. (2017). RelaçõesÉtnico Territoriais entre Guarani, Kaiowaì e Terena na Reserva Indiìgena de Dourados/MS. En Práticas e conflitos nos territórios dos povos indígenas GT realizado en el VIII Simposio Internacional de Geografias Agraria SINGA. Curitiba, Brasil.

O Progresso Digital Newspaper, KunPangueAtyGuasureuìne rezas, forças e sonhos Guaranis e Kaiowaìs(2017). Recuperado de www.progresso.com.br/cidades/ku-angue-aty-guasu-reune-rezas-forcas-e-sonhos-guaranise-kaiowas/299314/

Pacheco, R.A. S. (2017). Mulheres indígenas e participaçãopolítica: emergênciaétnica feminina em um contexto de expropriação territorial.Religación Revista de Ciencias Sociales y Humanidades,2 (8), 101114.doi:10.1590/18094449201800520007

Passos, L. R. B. (2007). Associações Indígenas: um estudo das relações entre Guarani e Terena na Terra Indígena de Dourados/ MS. Dissertação (Mestrado em Antropologia Social) . Universidade Federal do Paranaì. Curitiba.

Pereira, L. M. (2007). Mobilidade e processos de territorializac?aDo entre os Kaiowaì atuais. História em Reflexão, 1 (1), 1-35.doi: 10.30612

Pereira, L. M. (2008). A criançaKaiowá, o fogo doméstico e o mundo dos parentes: espaços de sociabilidade infantil. In: $32^{\circ}$ Encontro Anualda ANPOCS, Caxambu, MG.

Puiggros, O. C. (2016). Los feminismos indígenas de América Latina: diversidad de perspectivas y unidad de lucha. M. Painemal y Diaz, A. A. (comp.) Mujeres y pueblos originarios luchas y resistencias hacia la descolonización. Santiago, Chile. Pehueìn.

Radcliffe, S. (2014).El genero y la etnicidad como barreras para el desarrollo: Mujeres indiìgenas, acceso a recursos en Ecuador en perspectiva latinoamericana. Eutopia (5), agosto, 11-34. doi: 10.17141/ eutopia.5.2014.1486.

Sardenberg, C.M.B. (2010) Women's Empowerment in Brazil: tensions in discourse and practice.Society for International Development,53 (2), 232-238.doi: 10.1057/dev.2010.33.

Scherer-Warren, I. (2010).Movimentos sociais e pós-colonialismo na América Latina.Ciências Sociais Unisinos, 46(1), 18-27. doi:10.4013/csu.2010.46.1.03.

Seraguza, L. (2013).Cosmos, Corpos e Mulheres Kaiowá e Guarani de AnPa aì KunPa. (Tesis de maestria). Universidade Federal da Grande Dourados. Dourados, Brasil.

Unesco. La Unesco y la lucha contra el etnocídio: Declaración de San José. Dezembro de 1981. Recuperado de https://unesdoc.unesco.org/ark:/48223/pf0000049951_spa 
Vietta, K. (1998). Não tem quem orienta, a pessoa sozinha é que nem uma folha que vai com o vento: análise sobre alguns impasses presentes entre os Kaiowá/Guarani.Revista Divulgação Cultural(64), 15-24.

Vinding, D. (1998). Indigenous Women: The Right to a Voice. Copenhagen: IWGIA

Zibechi, R. (2015). Descolonizar el pensamiento crítico y las practicas emancipatorias. Bogotaì Colombia: Desde Abajo.

Zimmerman, T.R. e Viana, A.E. (2014). Apontamentos sobre gênero e violência contra mulheres indígenas Kaiowá e Guarani em Amambai/ MS (2007-2014).Tellus 14 (27), 117-128.http://dx.doi.org/10.20435/tellus.v0i27.311 